\title{
Selective regulation in ribosome biogenesis and protein production for efficient viral translation
}

\author{
Hui-Jun Dong ${ }^{1} \cdot$ Rui Zhang $^{1} \cdot$ Yu Kuang $^{1} \cdot$ Xiao-Jia Wang $^{1}$ (1)
}

Received: 7 July 2020 / Revised: 18 September 2020 / Accepted: 13 October 2020 / Published online: 29 October 2020

(c) Springer-Verlag GmbH Germany, part of Springer Nature 2020

\begin{abstract}
As intracellular parasites, viruses depend heavily on host cell structures and their functions to complete their life cycle and produce new viral particles. Viruses utilize or modulate cellular translational machinery to achieve efficient replication; the role of ribosome biogenesis and protein synthesis in viral replication particularly highlights the importance of the ribosome quantity and/or quality in controlling viral protein synthesis. Recently reported studies have demonstrated that ribosome biogenesis factors (RBFs) and ribosomal proteins (RPs) act as multifaceted regulators in selective translation of viral transcripts. Here we summarize the recent literature on RBFs and RPs and their association with subcellular redistribution, post-translational modification, enzyme catalysis, and direct interaction with viral proteins. The advances described in this literature establish a rationale for targeting ribosome production and function in the design of the next generation of antiviral agents.
\end{abstract}

Keywords Selective translation $\cdot$ Ribosome biogenesis factor $\cdot$ Ribosomal protein $\cdot$ Antiviral target

\section{Introduction}

Initiation, as the first stage of translation, can be carried out by either cap-dependent or cap-independent mechanism in eukaryotic cells (Kapp and Lorsch 2004). The majority of the eukaryotic genome is translated via cap-dependent translation initiation, mainly through the $43 \mathrm{~S}$ preinitiation complex (PIC) binding to the mRNA 5'-end cap structure and scanning along the mRNA to the AUG initiation codon to initiate translation (Haimov et al. 2015). In contrast to the cap-dependent mechanism, the cap-independent mechanism is translated by 43S PIC (or a single 40S unit in some specific mRNA templates) directly binding to the internal ribosome entry site (IRESs) in the genome intergenic region

Communicated by Erko Stackebrandt.

Rui Zhang

2015001@cau.edu.cn

$\triangle$ Yu Kuang

kuangyu@cau.edu.cn

Xiao-Jia Wang

wangxj@cau.edu.cn

1 Key Laboratory of Animal Epidemiology of the Ministry of Agriculture, College of Veterinary Medicine, China Agricultural University, Beijing 100193, China
(Kapp and Lorsch 2004). The number and types of translation initiation factors required for IRES-mediated translation initiation can vary significantly among specific mRNA species. For example, eIF4E is not required for IRES-mediated picornavirus genome translation (Avanzino et al. 2017), and IRES elements present in the hepatitis $\mathrm{C}$ virus (HCV) genome require fewer translation initiation factors to initiate translation (Torrecilla et al. 2016; Kerr et al. 2016).

Ribosomes are apparatuses that catalyze protein synthesis. The eukaryotic $80 \mathrm{~S}$ ribosome is composed of two subunits: the $40 \mathrm{~S}$ subunit contains the decoding center, which monitors the complementarity of transfer RNA (tRNA) and messenger RNAs (mRNA) and is composed of 33 ribosomal proteins (RPs), and the 60S subunit, which catalyzes the formation of peptide bonds and is composed of 47 RPs (Khatter et al. 2015; Barna 2013). Ribosome biogenesis is a complex process, which takes place mainly within the nucleoli of eukaryotes, and requires more than 300 ribosomal biogenesis factors (RBFs) (Tafforeau et al. 2013). RPs are coordinated with ribosomal RNA (rRNA) to synthesize, mature, assemble, and export into the cytoplasm, and they are crucial participants in the cellular process of translation from mRNA (Lafontaine and Tollervey 2001; Moore 2012).

Ribosome-mediated translational regulation can be explained by two different models (Shi et al. 2017; Simsek et al. 2017). The ribosome-concentration hypothesis 
proposes that the changes in cellular ribosome abundance may be a major driver of changes in translation of mRNA pools. The specialized ribosomes hypothesis is based on the finding that some RPs differ in composition and specifically regulate a subset of specific mRNA (such as RPL38 for Hox mRNA) translation (Shi and Barna, 2015; Xue and Barna, 2012; Simsek et al. 2017; Briggs et al. 2017; Genuth and Barna, 2018). RBFs control ribosome biogenesis to participate in the cellular process of mRNA translation. Several viruses have evolved sophisticated mechanisms that utilize cellular translational machinery to obtain efficient viral protein synthesis and viral replication (Hilton et al. 1986; Narayanan et al. 2008; Li et al. 2018a, b).

The ribosome itself (primarily ribosomal proteins), and the ribosomal biogenic processes that are exploited by viruses to facilitate their own replication, should be considered as targets in the development of antiviral agents, as depicted in Table 1 and as summarized in this study.

\section{The roles of ribosome biogenesis in viral replication}

Ribosome biogenesis is critical for cell proliferation and stress response. The synthesis of viral proteins depends on the host ribosome, and ribosome biogenesis has implications for viral infection through the effects of RBFs on viral transcription, proliferation, and antiviral immune responses, as well as the effects of viral proteins on ribosomal biosynthesis.

\section{Regulation of RBFs in viral infection}

Ribosomal RNA transcription, catalyzed by RNA polymerase I (Pol I), plays a critical role in ribosome biogenesis. Transcriptional activation of rRNA is also closely associated with viral infection. However, restricting ribosome biogenesis by interfering with rRNA accumulation-triggered ribosomal stress stimulated the viral replication of human cytomegalovirus (HCMV); the process inhibited the expression of innate immune-related genes, such as the high-mobility group Box 2 (HMGB2). This reveals that rRNA accumulation and/or ribosome biogenesis regulate innate immune responses to restrict virus reproduction and regulate inflammation (Bianco and Mohr 2019). Similarly, ribosomes are required for the protein synthesis of host cells and viruses, but the biogenesis factor RBFs can also impact the proliferation of virus and cell-intrinsic immune responses.

At this intersection of apparently competing processes, it is intriguing to find RBFs that are required specifically for the viral protein biosynthesis, but do not affect global translation. NOP53 (GLTSCR2/PICT-1), for example, shares homology with the yeast $60 \mathrm{~S}$ ribosomal protein Nop53p, which acts as an essential ribosome biogenesis factor (Sydorskyy et al. 2005; Thomson et al. 2005). A previous study by the present author showed that NOP53, expressed as a set of discrete globular structures within the nucleolus, is migrated to the cytoplasm upon infection by herpes simplex virus 1 (HSV-1) (Meng et al. 2018). Furthermore, the cytoplasmic translocation of NOP53 is required for efficient viral replication, which occurs via depression of the activity of innate immune receptor RIG-I and decrease of the phosphorylation level of eIF $2 \alpha$ to facilitate the production of viral proteins without affecting global protein synthesis (Meng et al. 2018, 2019). Similarly, both nucleolar proteins of ribosomal RNA processing 1 homolog B (RRP1B) and nucleolin are involved in ribosomal biogenesis (Chamousset et al. 2010). RRP1B associated with pre-60S ribosomal subunits was translocated to the nucleoplasm upon viral infection of influenza virus, where RRP1B improves viral RNA-dependent RNA polymerase (RdRp) activity, which is responsible for virus transcription and replication ( $\mathrm{Su}$ et al. 2015). Nucleolin, which is thought to control RNA metabolism and ribosome biogenesis (Cong, et al. 2012; Allain 2000), is prevented from entering the nucleus in poliovirusinfected cells (Waggoner 1998); this allows stimulation of IRES-mediated translation of viral transcripts (Izumi 2001). Upstream binding factor (UBF) plays a major role in the regulation of rRNA synthesis and associates with viral replication of adenovirus; the antibody against UBF reduces viral replication (Lawrence et al. 2006).

In mammalian cells, there are two sets of ribosome particles, which reside in the cytoplasm and the mitochondria. Some viruses manipulate mitochondrial biogenesis to support replication. It has been reported that the protein levels involved in mitochondrial ribosome biogenesis are significantly up-regulated by infection with human cytomegalovirus (HCMV). The inhibition of mitochondrial translation with chloramphenicol or knockdown of ribosome biogenesis factor MRM3 abolished the HCMV-mediated increase in mitochondrial coding proteins and significantly impaired viral growth (Karniely et al., 2016).

\section{Regulation of ribosome biogenesis in the nucleolus by viral proteins}

The main function of the nucleolus is in ribosome biogenesis, regulation of the cell cycle, and the response to cellular stress. Many viral proteins, such as the nucleocapsid protein of coronavirus (Chen et al. 2002; Cawood et al. 2007; Dove et al. 2006; Emmott et al. 2010; Hiscox et al. 2001; You et al. 2005), the matrix protein of Newcastle disease virus (NDV) (Peeples et al. 1992), and the non-structural protein 1 of influenza virus (Melén et al. 2002), transport to the nucleolus to regulate ribosome biosynthesis, change the nucleolar morphology, or affect the function of the 
Table 1 Ribosomal proteins and ribosome biogenesis factors utilized for viral infection

\begin{tabular}{|c|c|c|c|}
\hline RPs/RBFs & Virus & Functions for viral infection & Reference \\
\hline RPSA & FMDV & $\begin{array}{l}\text { FMDV VP1 interacts with RPSA to promote viral replica- } \\
\text { tion }\end{array}$ & Zhu et al. 2019 \\
\hline RPS5 & $\mathrm{HCV}$ & $\begin{array}{l}\text { Interacts with the IRES of HCV for optional translation of } \\
\text { viral transcripts }\end{array}$ & Fukushi et al. 2001; Bhat et al. 2015 \\
\hline \multirow[t]{2}{*}{ RPS6 } & $\mathrm{HCV}$ & Acts as an indispensable host factor for $\mathrm{HCV}$ propagation & Huang et al. 2012 \\
\hline & KSHV & $\begin{array}{l}\text { Interacts with the latency-associated nuclear antigen of } \\
\text { KSHV }\end{array}$ & Chen et al. 2011 \\
\hline RPS9 & $\mathrm{HCV}$ & $\begin{array}{l}\text { Interacts with the IRES of HCV for optional translation of } \\
\text { viral transcripts }\end{array}$ & Fukushi et al. 2001 \\
\hline RPS3 & HIV-1 & Interacts with viral Tat to inhibit cell proliferation & Kim and Kim 2018 \\
\hline RPS2 & WNV, DENV, YFV & Acts as receptor interacting with viral envelope protein $\mathrm{E}$ & Zidane et al. 2012 \\
\hline RPS19 & Hantavirus & $\begin{array}{l}\text { Required for initiation of viral nucleocapsid protein-medi- } \\
\text { ated translation }\end{array}$ & Cheng et al. 2011 \\
\hline RPS20 & Poxvirus & $\begin{array}{l}\text { Ubiquitination is specifically required for synthesis of viral } \\
\text { proteins }\end{array}$ & DiGiuseppe et al. 2018 \\
\hline RPS25 & $\begin{array}{l}\text { CrPV, HCV, HTLV-1, Poliovi- } \\
\text { rus, Adenovirus }\end{array}$ & Required for initiation of viral IRES-mediated translation & $\begin{array}{l}\text { Landry et al. 2009; Hertz et al. 2013; } \\
\text { Olivares et al. } 2014\end{array}$ \\
\hline RPS27 & IAV & Facilitates viral replication and infectivity & Karlas et al. 2010 \\
\hline RPS27a & EBV & $\begin{array}{l}\text { Enhances viral proliferation and invasion by stabilizing } \\
\text { LMP1 }\end{array}$ & Hong et al. 2017 \\
\hline RACK1 & $\mathrm{HCV}$ & Facilitates initiation of viral IRES-mediated translation & Majzoub et al. 2014; Ullah et al. 2019 \\
\hline \multirow[t]{2}{*}{ RPL4 } & IBDV & $\begin{array}{l}\text { Modulates viral replication as interaction partner of viral } \\
\text { VP3 protein }\end{array}$ & Chen et al. 2016 \\
\hline & EBV & $\begin{array}{l}\text { Acts as essential host factor for EBV Nuclear Antigen } 1 \\
\text { function }\end{array}$ & Shen et al. 2016 \\
\hline RPL6 & HTLV-1 & Facilitates proliferation of HTLV-I & Wang et al. 2002 \\
\hline \multirow[t]{2}{*}{ RPL7 } & HIV-1 & Facilitates virus particle assembly as a Gag binding partner & Mekdad et al. 2016 \\
\hline & WSSV & Interacts with VP51 to participate in WSSV infection & Liu et al. 2015 \\
\hline RPL9 & MMTV & Facilitates virus particle assembly as a Gag binding partner & Beyer et al. 2013 \\
\hline RPL18 & RSV & $\begin{array}{l}\text { Interacts with nucleocapsid protein to participate in RSV } \\
\text { infection }\end{array}$ & Li et al. 2018a, b \\
\hline RPL40 & VSV, RABV & Promotes efficient translation of viral transcripts & Lee et al. 2015 \\
\hline RPLP1/P2 & DENV, YFV, & $\begin{array}{l}\text { Act as essential host factors for early viral protein accumu- } \\
\text { lation }\end{array}$ & Campos et al. 2017 \\
\hline RPL10a & ZIKV HCV, CrPV & Regulate viral IRES-mediated translation & Shi et al. 2017 \\
\hline RPL13 & FMDV & $\begin{array}{l}\text { Interacts with viral IRES in helicase DDX3-dependent } \\
\text { manner }\end{array}$ & Han et al. 2019 \\
\hline NOP53 & HSV-1 & $\begin{array}{l}\text { Cytoplasmic translocation associated with efficient viral } \\
\text { replication }\end{array}$ & Meng et al. 2018; 2019 \\
\hline RRP1B & IAV & Acts as essential host factors for IAV transcription & Su et al. 2015 \\
\hline Nucleolin & Poliovirus & $\begin{array}{l}\text { Stimulates IRES-mediated translation of the poliovirus } \\
\text { genome }\end{array}$ & Izumi et al. 2001 \\
\hline MRM3 & HCMV & $\begin{array}{l}\text { Essential host factor for mitochondrial coding proteins and } \\
\text { viral replication }\end{array}$ & Karniely et al. 2016 \\
\hline $\mathrm{UBF}$ & Adenovirus & Associates with the replication of viral DNA & Lawrence et al. 2006 \\
\hline NPM & HBV & Interacts with $\mathrm{HBx}$ and mediates its oncogenic effects & Ahuja et al. 2015 \\
\hline DDX5 & SARS-CoV, IBV, HIV-1, HCV & Recruited by viral proteins to facilitate viral replication & $\begin{array}{l}\text { Chen et al. 2009; Zhou et al. 2013; } \\
\text { Goh et al. 2004; Bortz et al. 2011 }\end{array}$ \\
\hline
\end{tabular}

nucleolus. During nucleocytoplasmic shuttling, viral proteins can recruit nucleolar RBFs to modulate ribosomal biosynthesis for efficient viral replication. The multifunctional nucleolar phosphoprotein nucleophosmin (NPM) plays a lead role in ribosome biogenesis to stimulate RNA Pol I-dependent transcription ( $\mathrm{Li}$ and Hann 2013) and regulates 
the export of ribosomal proteins and mature ribosomes to the cytoplasm (Yu et al. 2006). The HBx oncoprotein of hepatitis B virus (HBV) directly interacted with the C-terminal domain of NPM to stimulate viral transcription (Ahuja et al. 2015). Several RNA helicases have been demonstrated to facilitate ribosome biogenesis, involving the processing of ribosomal RNA (rRNA) as well as its assembly into functional ribonucleoprotein complexes (Bleichert et al. 2007). DDX5 promotes the synthesis and maturation of rRNA and ultimately increases ribosome output and proliferation (Jalal et al. 2007). Many viral proteins, such as coronavirus nsp 13 (Chen et al. 2009), Rev of human immunodeficiency virus 1 (HIV-1) (Zhou et al. 2013), NS5B of hepatitis C virus (HCV) (Goh et al. 2004), and NP protein of influenza virus (Bortz et al. 2011) have evolved to hijack DDX5 in order to facilitate viral replication. Studies on the regulation or manipulation of viral protein in ribosome biosynthesis provides new insights into efficient viral replication.

\section{The roles for RPs in canonical translation and cap-independent translation}

The ribosome was once considered to be a large protein synthesis machine that merely translated mRNAs into proteins. In recent years, however, the role of ribosomes in the regulation of initiation and selection of mRNAs has been the subject of increased attention. Most RPs are essential for translation and viral replication, and regulate translation of viral mRNAs as constituents of the ribosome, although a few represent the defense signaling of host cells (Zhou et al. 2015). (The role of RPs in activating an immune response is beyond the scope of the present paper.) Of particular interest are the RPs that are non-essential to the function of the ribosome, such as the large ribosomal subunit (RPL40, RPL38) and the small ribosomal subunit (RPS27, RPS25) (Jack et al. 2011; Karlas et al. 2010; Xue et al. 2015; Lee et al. 2013).

In the process of coevolution with hosts, viruses have evolved different strategies to inhibit host translation or induce host translation shutoff while protecting their own protein synthesis. Many viruses globally interfere with host translation by impairing cap-dependent ribosome recruitment to host mRNAs. For example, vesicular stomatitis virus (VSV) inhibits the translation of host mRNAs in infected cells, but allows the translation of its own capped mRNAs (Whitlow et al. 2008; Wertz and Youngner 1970). RPL40 promotes efficient translation of VSV mRNAs in a cap-dependent manner, but is not required for global protein synthesis (Lee et al. 2013). This may represent an endogenous specialized translation function for RPL40. Influenza A virus (IAV) viral mRNAs, on the other hand, are not preferentially translated compared to their host counterparts, and the extensive translation of viral proteins is the result of viral takeover of the mRNA pool in the cell (Bercovich-Kinori et al. 2016). Ribosome footprints and mRNA read density analysis reveal that RPs are not strongly affected by IAV infection but are enriched for genes involved in pathways that the virus may depend on (Bercovich-Kinori et al. 2016). Moreover, IAV encodes C4-type zinc finger peptide (ZFP) motif-containing viral protein (such as matrix protein M1) for replication and virus budding (Fernandez-Pol et al. 2001); RPS27 also contains a ZFP motif, and has recently been reported to facilitate translation and viral replication (Fernandez-Pol et al. 2001; Fernandez-Pol 2011). When RPS27 is eliminated, the replication and infectivity of IAV is abolished, but it is dispensable for global protein synthesis (Karlas et al. 2010). Research on the essential viral and cellular ZFP motif-containing proteins has implications for the prevention and therapy of viral diseases, and these proteins should be considered as targets for novel antiviral compounds.

In eukaryotes, certain RPs control selectivity during IRES-driven translation. For example, RPL38 and RPL35 control the selective translation of a specific mRNA by promoting translation primarily at the initiation stage (Kondrashov et al. 2011; Jiang et al. 2015; Xue et al. 2015). Several viruses whose genomes lack a 5'-end cap structure use capindependent mechanisms for translation initiation (Daijogo and Semler 2011; Martinez-Salas et al. 2015). These viruses have in fact evolved to hijack specific RPs to achieve optimal viral protein synthesis; they facilitate translation of viral transcripts of IRES-containing viruses. The RPs include RPS25 (Landry et al. 2009), RPS5 (Fukushi et al. 2001; Bhat et al. 2015), RPS6 (Huang et al. 2012), RPS9 (Fukushi et al. 2001), and RACK1 (Majzoub et al. 2014), as well as RPL10a (Shi et al, 2017), RPL22 (Wood et al. 2001), and RPLp1/2 (Campos et al. 2017). Of these, RACK1 (Majzoub et al. 2014) and RPS6 (Huang et al. 2012) are specifically required for IRES activity in various types of viral IRESs. RPL10a regulates translation from the HCV and cricket paralysis virus (CrPV) IRESs but not from the encephalomyocarditis virus (EMCV) IRES (Shi et al, 2017). In other words, RPL10a is an example of an RP that plays a specific role in promoting translation of particular classes of viral IRESs. RPS25 is essential for initiation from the HCV and CrPV IRES (Landry et al. 2009). RPS25 deletion in yeast or mammalian cells has minimal effects on cellular protein synthesis, which implies that this ribosomal protein may be selectively required for viral IRES-mediated translation (Jack et al. 2011; Hertz et al. 2013). Similarly, RACK1 is not required for cellular IRESs or global synthesis (Majzoub et al. 2014). Overall, RPs specifically required for protein synthesis in particular viruses but not for global synthesis may provide an effective target for methods to fight viral infection. 


\section{Alterations in functional characteristics of RPs for viral translation}

Some of the related functions of RPs are ribosome-dependent, as when RPs participate in viral protein biosynthesis, and other functions, typically involved in the regulation of infection in host cells, are independent of the ribosome. Alterations in RP characteristics for optional translation are implicated in interaction with viral proteins, post-translational modification, and redistribution, directly or with the assistance of RNA helicase.

\section{RPs interact with viral proteins}

Some viruses have developed to hijack specific RPs using viral proteins to achieve optimal viral translation. IBDV VP3 is a multifunctional protein playing a key role in virus assembly and pathogenesis. Ribosomal protein L4 (RPL4) (Chen et al. 2016) and ribosomal protein L18 (Wang et al. 2018) were identified as interacting partners of VP3 protein and as being involved in the regulation of IBDV replication. RPL18 interacts with nucleocapsid protein of rice stripe tenuivirus (RSV), and silencing RPL18 significantly reduces viral mRNA translation and replication of RSV (Li et al. 2018a, b). RPL7 interacts with the VP51 to participate in viral infection of white spot syndrome virus (WSSV), and the addition of anti-RPL7 antibody inhibits WSSV infection in Litopenaeus vannamei (Liu et al. 2015). Among flaviviruses, the envelope protein of West-Nile virus (WNV), dengue virus (DENV), and yellow fever virus (YFV) bind with RPSA, which serves as the viral receptor (Zidane et al. 2012). As regards alphaviruses, RPSA includes different binding sites for Venezualian equine encephalitis virus (VEEV) and Sindbis virus (SINV) (Jamieson et al. 2008; Malygin et al. 2009). HIV-1 Tat inhibits cell proliferation via an interaction with RPS3 and increases the level of RPS3 in the nucleus, thereby disrupting mitotic spindle formation during HIV-1 infection (Kim and Kim 2018). FMDV VP1 inhibits the antiviral response of RPSA by interacting with RPSA to promote FMDV replication (Zhu et al. 2019). Binding of viral proteins to specific RPs plays a crucial role in viral infection. Effective inhibition of the binding between RPs and viral proteins can be a potential target for antiviral design.

\section{Post-translational modification of RPs}

Post-translational modifications such as phosphorylation, ubiquitination, acetylation, methylation, or O-GlcNAcylation activate, deactivate, or modify RP's functions. Over 2,500 modifications of human RPs have been reported; these modifications impact RP activity and subsequently modify the global rate of translation by modulating initiation, elongation, and termination rates (Emmott et al. 2019). One wellstudied modification on the ribosome is phosphorylation following activation or inhibition of intra and extracellular signaling cascades in response to stimuli occurring in physiological or pathological conditions (Emmott et al. 2019). Phosphorylation of RPS6 is perhaps the most widely studied ribosomal protein phosphorylation among the RPs involved in virus infection; it is induced by various viral infections (Kennedy et al. 1981; Kennedy and Leader 1981; Decker 1981; Banham et al. 1993; Beaud et al. 1994). In addition, an early study revealed that phosphorylation of RPL30 was induced by herpes simplex virus-1 (HSV-1) (Simonin et al. 1995). RPSa, RPS 2 and RPS13 appear specifically phosphorylated in cells early after infection with vaccinia virus (Kaerlin and Horak 1978; Buendia et al. 1987). Efficient phosphorylation of the ribosomal proteins correlates well with possible translational mechanisms, ensuring efficient expression of early and late genes of vaccinia virus. It has been shown that phosphorylation of the RACK1A protein on two residues-Ser-122 and Thr162-by an atypical serine/ threonine protein kinase WNK8 (With No Lysine8) negatively regulates RACK1A function in the glucose responsiveness pathway by influencing its protein stability (Urano et al. 2015). RACK1A proteins are phosphorylated by tyrosine, depending on diverse environmental stresses (Sabila et al. 2016). Viral infection leads to activation of ribosomal protein phosphorylation, which may be closely related to effective viral translation. The change of phospho-RP level may affect viral translation. However, despite reports on the increasing phosphorylation of RPs induced by viral infection (Emmott et al. 2019; Diaz et al. 2002), the details of the role of this modification in virus infection remain poorly understood.

Another extensively studied post-translational modification on the ribosome is ubiquitylation, or covalent bonding of ubiquitin to substrate proteins for disposal by the proteasome (degradative ubiquitylation) or alteration of the function of the protein (regulatory ubiquitylation) (Haas et al. 1982; Thrower et al. 2000). Degradative ubiquitylation is important for ribosome-independent function. In fact, excess RPs that are not incorporated into the ribosome are degraded by the proteasome (Lam et al. 2007; Genuth and Barna, 2018). Several RPs have been shown to be dynamically ubiquitylated in response to cellular conditions; RPS2, RPS3, and RPS20, for instance, undergo regulatory ubiquitylation during the unfolded protein response (UPR) in yeast, fruit fly, and human cell lines (Higgins et al. 2015). Notably, the ubiquitination of RPS20 was found to be specifically required for viral replication and synthesis of poxvirus proteins (DiGiuseppe et al. 2018). In addition to ubiquitin, other related proteins have been found to modify the ribosome. 
RPL26, for instance, is the principal target of UFM1 conjugation, a ubiquitin-related modification (ufmylation), and UFMylated RPL26 is highly enriched on ER membranebound ribosomes and polysomes (Walczak et al. 2019; Wang et al. 2019). UFM1 is also conjugated to RPS3, RPS20, and RPL10 (Simsek et al. 2017). The overlap of ufmylation and ubiquitylation on RPS3 and RPS20 also occurs, and this suggests that certain RPs have combinatorial modifications. O-GlcNAcylation modification was also found to be activated in response to adverse stress to protect cellular proteins from damage (Zachara and Hart 2004, 2006; Slawson et al. 2006). In the stress response, O-GlcNAc-modified proteins are prominent components of stress granules, including small and large ribosomal subunit proteins (RPS3, 9, 11 and 24, and RPL6, 13a, 14, 30 and 36a-like) and the ribosomeassociated protein RACK1 (Ohn et al. 2008). Although the effect of RP O-GlcNAcylation on viral infection has been as yet little studied, we can to some extent understand RP O-GlcNAcylation under viral infection through other forms of cellular stimulation, and start to develop an understanding of the possible role of post-translational modification of RPs in antiviral strategy.

\section{The redistribution of RPs to different subcellular compartments}

Although RPs are all synthesized in the cytoplasm, they assemble into functional subunits in different subcellular compartments (Kressler et al. 2010; Li 2019). Sometimes, ribosomal proteins change their localization under virus infection to exercise functions outside the ribosome. RPL22, for instance, is translocated from the nucleoli to the nucleoplasm and colocalized with ICP4 in infection by HSV-1. The location change of RPL22 plays a role in the regulatory functions expressed by ICP4 (Leopardi and Roizman, 1996). In another example of similar function, after DENV infection, RPL18 is redistributed to the perinuclear region for regulation of viral replication (Cervantes-Salazar et al. 2015). In eukaryotic cells, acidic ribosomal protein RPLp0 binds two P1/P2 protein heterodimers to form a pentameric P-stalk (Ballesta et al. 1996; Naganuma et al. 2007). Eukaryotic RPLp1 and RPLp2 proteins also exist in free form in the cytoplasm, and the exchange between the ribosome-bound RPLp1 and RPLp2 proteins and the cytoplasmic pools is thought to regulate the activity of the ribosome (Lee et al. 2010). This property may lead to changes in the localization of RPLp1/2 in the ribosome and cytoplasmic pools under stress conditions. Viral infection is one of numerous possible stress stimuli, so viral infection may cause RPLp1/2 to produce this subcellular compartment exchange to affect virushost translation regulation. Under nucleolar stress induction, RPLp0 accumulates in the cytoplasm of mammalian cells as a free, ribosome-unbound protein (Deryło et al. 2018). A ribosome-free pool of RPLp0 has been shown to be a population of proteins released from pre-existing ribosomes. The presence of RPLp0 on the ribosome seems to be affected in stressed cells, and it might be considered as a regulatory element responding to environmental fluctuations. In addition, the mitochondrial RPs (MRPs) are encoded by nuclear genes and then imported into mitochondria for assembly; they are responsible for the translation of 13 mitochondrial mRNAs (Christian and Spremulli 2012). Mitochondrial RPL18 acts as a critical regulator of the stress response and generates a cytosolic isoform in a stress-dependent manner. The cytosolic RPL18 is incorporated into the $80 \mathrm{~S}$ ribosome and facilitates ribosome engagement in heat-shock protein (HSP) mRNA translation to escape from the shutoff of global protein synthesis during stress (Zhang et al. 2015).

\section{RPs cooperate with RNA helicase to facilitate virus initiation translation}

Accumulating evidence has revealed the roles of RPs belonging to the large $60 \mathrm{~S}$ subunit in regulating selective translation of specific mRNAs, although they are primarily involved in catalyzing peptide-bond formation (Wilson et al. 2012). A previous study by the present author identified RPL13 as a critical regulator of IRES-driven translation during foot-and-mouth disease virus (FMDV) infection, but found that it is not essential for cellular global translation (Han et al. 2020). Our results support a model whereby the viral IRESs recruit helicase DDX3 downstream of the RPL13 to facilitate IRES-driven translation and viral replication. Specifically, the depletion of DDX3 disrupts binding of RPL13 to the FMDV IRES, whereas the reduction in RPL13 expression impairs the ability of DDX3 to promote IRES-driven translation directly. This work was the first to identify a connection between DDX3 and RPs in modulating viral IRES-dependent translation (Han et al. 2020). DDX3 is well known, however, to play roles in various key aspects of RNA metabolism, including transcriptional regulation, splicing, mRNA export, ribosome biogenesis, and translational regulation (Chuang et al. 1997; Rocak and Linder 2004; Guenther et al. 2018). Improved knowledge about these RNA helicases and their relation to translation initiation could have important implications for the understanding of selective translation of viral mRNA, and thus for the development of effective antivirals.

\section{Translation regulators as specific targets for antiviral design}

The strategy of targeting a host factor, instead of the virus directly, could circumvent the danger of resistance in mutation-associated variations and the evolution of new viral 
variants after prolonged use of otherwise-promising antiviral drugs. After 60 years of research on ribosomes, the ribosome has emerged as a major player in translational regulation, and its place in the list of potential antiviral therapeutic targets has been reinforced. Targeting the ribosome, either biogenesis or function, may provide an efficient and focused approach for design of antiviral agents.

As our understanding of the function of RBFs and RPs in viral translation has evolved, the design of therapeutic strategies for RBFs and RPs has been explored. Recent structural analysis of prokaryotic and eukaryotic ribosomes has demonstrated that certain molecules, including some antibiotics and chemical inhibitors of translation, can bind to the ribosome (Svetlov et al. 2017; Tereshchenkov et al. 2018). CX-5461, for example, is a ribosomal biogenesis inhibitor that disrupts RNA Pol I-mediated transcription (Drygin et al. 2011), and inhibits viral DNA synthesis and virus production in the early and late stages of the HCMV infection (Westdorp and Terhune 2018). Toyocamycin is a small molecule inhibitor of Rio1 kinase activity (Kiburu et al. 2012); Rio1 is an essential ribosome biogenesis factor required for maturation of $40 \mathrm{~S}$ ribosomal subunit (Angermayr et al. 2002). Toyocamycin inhibits ribosome biogenesis to produce antiviral effects (Ríman et al. 1969). Notably, translation of IRES-containing viruses (such as HCV, HTLV-1, CrPV, poliovirus, and adenovirus) is dependent on RPS25 (Landry et al. 2009; Hertz et al. 2013; Olivares et al. 2014), and its activity is highly sensitive to the antibiotic Edeine (Olivares et al. 2014). Picolinic acid (PA) and fusaric acid (FU) disrupt the ZFP motifs of RPS27 or crucial viral proteins to produce antiviral effects (Yu et al. 1995; Everett et al. 1993; Wakefield and Brownlee 1989; Love et al. 1996). Ricin is an RPLp protein inhibitor (May et al. 2012); RPLp1/2 is an essential host factor for flavivirus replication (Campos et al.2017). RACK1 is essential for the translation of many viruses, including HCV, Drosophila C (DCV), Cricket Paralysis (CrpV) (Majzoub et al. 2014), and vaccinia viruses (Jha et al. 2017). Thus, RACK1 inhibitors may be developed as novel antiviral therapeutics. The drug SD-29 and analogues show high efficacy in inhibition of virus proliferation (Ullah et al. 2019). Exploring strategies for targeting RBFs and RPs is a natural path for further study in this field.

Once the function of RBFs and RPs in viral translation is understood, targeting inhibitors will need to be identified, designed, and screened. To accelerate the process of drug discovery for both novel targets and existing targets that suffer from drug resistance, basic platforms for drug design and screening are required. In a recent study, structure-based screening of two million commercially available compounds was used to screen for small molecules to target the RACK1 Y248 phosphorylation site. (As noted, host RACK1 protein is an attractive target for developing broad antiviral drugs.)
Dozens of small compounds were identified that could potentially bind to the experimentally determined functional site of the RACK1A protein; the drugs show high efficacy in inhibition of the proliferation of viruses that require RACK1 for translation (Ullah et al. 2019). This approach can be used to study the ribosomal proteins that are essential for the translation of many viruses, and eventually to design broad-spectrum antiviral drugs. Furthermore, depletion of regulatory RBFs and RPs is not essential for basic ribosomal function in experiments, making them potential targets for the design of small molecule antiviral drugs. RNA interference (RNAi) and strategies based on CRISPR/cas9 are also promising approaches in targeting of RBF and RP genes. Of course, projecting forward to the practical application of antiviral drugs, the adverse cell response caused by targeting of RBF and RP genes must be studied in detail.

\section{New approaches to identification of RP production and function}

Deciphering the functional details of translation of viral mRNA will require the in-depth scrutiny of RPs. A number of technological efforts have been made over the last decade to facilitate exploration of RP biogenesis and functions. Ribosome profiling is an emerging technique that allows the distribution of ribosome units on each transcript to be obtained, enabling systematic probing of translation and increased sensitivity and efficiency. This method, in conjunction with RNA-seq, has been used to probe the complex viral replication of several viruses (Yang et al. 2015; Irigoyen et al. 2016). Using high-coverage tandem mass tag (TMT) mass spectrometry, the relative monosome and polysome fractions of each RP were compared. A thorough examination of each RP revealed that some RPs (such as RPS9 and RPL11) are more abundant in monosomes than in polysomes (Slavov et al. 2015). TMT technology has been extended to the investigation of potential heterogeneity of RPs. Mass spectrometry has also been improved to address directly and more accurately the possibility of variability in RP stoichiometry. This novel technology, called selected reaction monitoring (SRM)-based proteomics, uses the spiking of samples with known amounts of labeled peptides derived from RPs as a standard for absolute quantification. Using this technology, absolute quantification of 15 RPs isolated from polysomes was assessed and 4 RPs, RPL10A, RPL38, RPS7, and RPS25, were identified as being substoichiometric in murine ESC ribosomes (Shi et al. 2017). Based on this technology, the heterogeneity in ribosome composition within a single cell type and a single polysome profile fraction was revealed for the first time. These approaches provide a starting point in the attempt to identify and quantify each RP expression profile in cells challenged with viruses, 
and at different infectious stages. In a recent study, both the small and large ribosomal subunits in mouse ESCs were endogenously tagged, and affinity enrichment for each of the tagged ribosomal subunits was performed to define the intersection of the two separate ribosomal subunit datasets. This has led to the identification of ribosome-associated proteins (RAPs), which fall into unexpected functional categories, such as energy metabolism, cell cycle, and key protein and RNA modification enzymes (Simsek et al. 2017). This method may facilitate identification of a series of proteins (such as RAPs) that are specifically recruited to ribosomes with the assistance of RPs, and act as potential targets for antiviral therapeutic design. Technical limitations have thus far impeded the study of selective translation mediated by RPs in viral infection, and considerable research will be required before clinical application of viral therapeutics based on the targeting of RPs.

\section{Conclusions and path forward}

Historically, the ribosome has been viewed as a complex ribozyme, and ribosome activity has been considered to be highly regulated. Although the concepts of ribosome heterogeneity and specialization at the level of core RPs are still in infancy, solid data have been published in various areas, offering convincing evidence that the ribosome plays a constitutive role as well as a regulatory function in translation. Moreover, constitutive components of the ribosome may perform more specialized activities by virtue of their interactions with specific mRNA regulatory elements, such as IRESs. These findings add numerous layers of subtlety to the conventional interpretation of translational regulation.

Viruses depend on host cell structures and translation systems to complete their life cycle. In order to survive in the host cell and achieve rapid replication and proliferation, viruses have developed various mechanisms to allow the selective translation of viral mRNA and repress cellular mRNA translation. Inducing host translation shutoff is a strategy used by many viruses to optimize their replication and spread by fostering viral protein synthesis and crippling host antiviral responses. In this process, some RPs are activated to promote the translation of specific transcripts, and thus the virus can still synthesize its own proteins to optimize their replication and spread when host translation is shut off.

In this review, we focus on the important role of RP production and function in viral or host translation processes that support viral replication and infection. Understanding the research on the specialized RBFs and RPs utilized by a virus can deepen the understanding of selective translation, and expand the depth and breadth of the field of virus-host interactions. This research, data, and theoretical evidence will facilitate the identification of antiviral targets and the eventual design of antiviral drugs, and advance the development of therapeutic strategies to produce optimal antiviral agents for effective control of viral diseases.

Acknowledgments This work was supported by the National Natural Science Foundation of China (31772739) and a CAU-Grant for the Prevention and Control of Immunosuppressive Disease in Animals (CAU-G-PCIDA) of the China Agricultural University.

\section{Compliance with ethical standards}

Conflict of interest The authors declare that they have no conflict of interest.

\section{References}

Ahuja R, Kapoor NR, Kumar V (2015) The HBx oncoprotein of hepatitis $B$ virus engages nucleophosmin to promote rDNA transcription and cellular proliferation. Biochim Biophys Acta 1853(8):1783-1795

Allain FH-T, Bouvet P, Dieckmann T, Feigon J (2000) Molecular basis of sequence specific recognition of pre-ribosomal RNA by nucleolin. EMBO J 19(24):6870-6881

Angermayr M, Roidl A, Bandlow W (2002) Yeast Rio1p is the founding member of a novel subfamily of protein serine kinases involved in the control of cell cycle progression. Mol Microbiol 44(2):309-324

Avanzino BC, Fuchs G, Fraser CS (2017) Cellular cap-binding protein, eIF4E, promotes picornavirus genome restructuring and translation. Proc Natl Acad Sci U S A 114(36):9611-9616

Ballesta JP, Remacha M (1996) The large ribosomal subunit stalk as a regulatory element of the eukaryotic translational machinery. Prog Nucleic Acid Res Mol Biol 55:157-193

Banham AH, Leader DP, Smith GL (1993) Phosphorylation of ribosomal proteins by the vaccinia virus B1R protein kinase. FEBS Lett 321(1):27-31

Barna M (2013) Ribosomes take control. Proc Natl Acad Sci U S A 110(1):9-10

Beaud G, Sharif A, Topa-Massé A, Leader DP (1994) Ribosomal protein S2/Sa kinase purified from HeLa cells infected with vaccinia virus corresponds to the B1R protein kinase and phosphorylates in vitro the viral ssDNA-binding protein. J Gen Virol 75(Pt 2):283-293

Bercovich-Kinori A, Tai J, Gelbart IA, Shitrit A, Ben-Moshe S, Drori Y, Itzkovitz S, Mandelboim M, Stern-Ginossar N (2016) A systematic view on influenza induced host shutoff. Elife 5:e18311

Beyer AR, Bann DV, Rice B, Pultz IS, Kane M, Goff SP, Golovkina TV, Parent LJ (2013) Nucleolar trafficking of the mouse mammary tumor virus gag protein induced by interaction with ribosomal protein L9. J Virol 87(2):1069-1082

Bhat P, Shwetha S, Sharma DK, Joseph AP, Srinivasan N, Das S (2015) The beta hairpin structure within ribosomal protein S5 mediates interplay between domains II and IV and regulates HCV IRES function. Nucleic Acids Res 43(5):2888-2901

Bianco C, Mohr I (2019) Ribosome biogenesis restricts innate immune responses to virus infection and DNA. Elife 8:e49551

Bleichert F, Baserga SJ (2007) The long unwinding road of RNA helicases. Mol Cell 27(3):339-352

Bortz E, Westera L, Maamary J, Steel J, Albrecht RA, Manicassamy B, Chase G, Martínez-Sobrido L, Schwemmle M, García-Sastre A (2011) Host- and strain-specific regulation of influenza 
virus polymerase activity by interacting cellular proteins. $\mathrm{mBio}$ 2(4):e00151-e211

Briggs JW, Dinman JD (2017) Subtractional heterogeneity: a crucial step toward defining specialized ribosomes. Mol Cell 67(1):3-4

Buendia B, Person-Fernandez A, Beaud G, Madjar J (1987) Ribosomal protein phosphorylation in vivo and in vitro by vaccinia virus. Eur J Biochem 162(1):95-103

Campos RK, Wong B, Xie X, Lu YF, Shi PY, Pompon J, GarciaBlanco MA, Bradrick SS (2017) RPLP1 and RPLP2 are essential flavivirus host factors that promote early viral protein accumulation. J Virol 91(4):e01706-e1716

Cawood R, Harrison SM, Dove BK, Reed ML, Hiscox JA (2007) Cell cycle dependent nucleolar localization of the coronavirus nucleocapsid protein. Cell Cycle 6(7):863-867

Cervantes-Salazar M, Angel-Ambrocio AH, Soto-Acosta R, Bautista-Carbajal P, Hurtado-Monzon AM, Alcaraz-Estrada SL, Ludert JE, Del Angel RM (2015) Dengue virus NS1 protein interacts with the ribosomal protein RPL18: this interaction is required for viral translation and replication in Huh-7 cells. Virology 484:113-126

Chamousset D, De Wever V, Moorhead GB, Chen Y, Boisvert FM, Lamond AI, Trinkle-Mulcahy L (2010) RRP1B targets PP1 to mammalian cell nucleoli and is associated with Pre-60S ribosomal subunits. Mol Biol Cell 21(23):4212-4226

Chen W, Dittmer DP (2011) Ribosomal protein S6 interacts with the latency-associated nuclear antigen of Kaposi's sarcomaassociated herpesvirus. J Virol 85(18):9495-9505

Chen H, Wurm T, Britton P, Brooks G, Hiscox JA (2002) Interaction of the coronavirus nucleoprotein with nucleolar antigens and the host cell. J Virol 76(10):5233-5250

Chen JY, Chen WN, Poon KM, Zheng BJ, Lin X, Wang YX, Wen YM (2009) Interaction between SARS-CoV helicase and a multifunctional cellular protein (Ddx5) revealed by yeast and mammalian cell two-hybrid systems. Arch Virol 154(3):507-512

Chen Y, Lu Z, Zhang L, Gao L, Wang N, Gao X, Wang Y, Li K, Gao Y, Cui H, Gao H, Liu C, Zhang Y, Qi X, Wang X (2016) Ribosomal protein L4 interacts with viral protein VP3 and regulates the replication of infectious bursal disease virus. Virus Res 211:73-78

Cheng E, Haque A, Rimmer MA, Hussein IT, Sheema S, Little A, Mir MA (2011) Characterization of the interaction between hantavirus nucleocapsid protein $(\mathrm{N})$ and ribosomal protein S19 (RPS19). J Biol Chem 286(13):11814-11824

Christian BE, Spremulli LL (2012) Mechanism of protein biosynthesis in mammalian mitochondria. Biochim Biophys Acta 1819(9-10):1035-1054

Chuang RY, Weaver PL, Liu Z, Chang TH (1997) Requirement of the DEAD-Box protein ded1p for messenger RNA translation. Science 275(5305):1468-1471

Cong R, Das S, Ugrinova I, Kumar S, Mongelard F, Wong J, Bouvet P (2012) Interaction of nucleolin with ribosomal RNA genes and its role in RNA polymerase I transcription. Nucleic Acids Res 40(19):9441-9454

Daijogo S, Semler BL (2011) Mechanistic intersections between picornavirus translation and RNA replication. Adv Virus Res 80:1-24

Decker S (1981) Phosphorylation of ribosomal protein S6 in avian sarcoma virus-transformed chicken embryo fibroblasts. Proc Natl Acad Sci U S A 78(7):4112-4115

Deryło K, Michalec-Wawiórka B, Krokowski D, Wawiórka L, Hatzoglou M, Tchórzewski M (2018) The uL10 protein, a component of the ribosomal P-stalk, is released from the ribosome in nucleolar stress. Biochim Biophys Acta Mol Cell Res 1865(1):34-47

Diaz JJ, Giraud S, Greco A (2002) Alteration of ribosomal protein maps in herpes simplex virus type 1 infection. J Chromatogr B Analyt Technol Biomed Life Sci 771(1-2):237-249
DiGiuseppe S, Rollins MG, Bartom ET, Walsh D (2018) ZNF598 plays distinct roles in interferon-stimulated gene expression and poxvirus protein synthesis. Cell Rep 23(5):1249-1258

Dove BK, You JH, Reed ML, Emmett SR, Brooks G, Hiscox JA (2006) Changes in nucleolar morphology and proteins during infection with the coronavirus infectious bronchitis virus. Cell Microbiol 8(7): 1147-1157

Drygin D, Lin A, Bliesath J, Ho CB, O’Brien SE, Proffitt C, Omori M, Haddach M, Schwaebe MK, Siddiqui-Jain A, Streiner N, Quin JE, Sanij E, Bywater MJ, Hannan RD, Ryckman D, Anderes K, Rice WG (2011) Targeting RNA polymerase I with an oral small molecule CX-5461 inhibits ribosomal RNA synthesis and solid tumor growth. Cancer Res 71(4):1418-1430

Emmott E, Smith C, Emmett SR, Dove BK, Hiscox JA (2010) Elucidation of the avian nucleolar proteome by quantitative proteomics using SILAC and changes in cells infected with the coronavirus infectious bronchitis virus. Proteomics 10(19):3558-3562

Emmott E, Jovanovic M, Slavov N (2019) Ribosome stoichiometry: from form to function. Trends Biochem Sci 44(2):95-109

Everett RD, Barlow P, Milner A, Luisi B, Orr A, Hope G, Lyon D (1993) A novel arrangement of zinc-binding residues and secondary structure in the $\mathrm{C} 3 \mathrm{HC} 4$ motif of an alpha herpes virus protein family. J Mol Biol 234(4):1038-1047

Fernandez-Pol JA (2011) Conservation of multifunctional ribosomal protein metallopanstimulin-1 (RPS27) through complex evolution demonstrates its key role in growth regulation in Archaea, eukaryotic cells, DNA repair, translation and viral replication. Cancer Genom Proteom 8(3):105-126

Fernandez-Pol JA, Hamilton PD, Klos DJ (2001) Essential viral and cellular zinc and iron containing metalloproteins as targets for novel antiviral and anticancer agents: Implications for prevention and therapy of viral diseases and cancer. Anticancer Res 21(2A):931-957

Fukushi S, Okada M, Stahl J, Kageyama T, Hoshino FB, Katayama K (2001) Ribosomal protein S5 interacts with the internal ribosomal entry site of hepatitis $\mathrm{C}$ virus. J Biol Chem 276(24):20824-20826

Genuth NR, Barna M (2018) Heterogeneity and specialized functions of translation machinery:from genes to organisms. Nat Rev Genet 19(7):431-452

Goh PY, Tan YJ, Lim SP, Tan YH, Lim SG, Fuller-Pace F, Hong W (2004) Cellular RNA helicase p68 relocalization and interaction with the hepatitis $\mathrm{C}$ virus (HCV) NS5B protein and the potential role of p68 in HCV RNA replication. J Virol 78(10):5288-5298

Guenther UP, Weinberg DE, Zubradt MM, Tedeschi FA, Stawicki BN, Zagore LL, Brar GA, Licatalosi DD, Bartel DP, Weissman JS, Jankowsky E (2018) The helicase Ded1p controls use of near-cognate translation initiation codons in 5' UTRs. Nature 559(7712):130-134

Haas AL, Warms JV, Hershko A, Rose IA (1982) Ubiquitin-activating enzyme mechanism and role in protein-ubiquitin conjugation. $\mathrm{J}$ Biol Chem 257(5):2543-2548

Haimov O, Sinvani H (1849) Dikstein R (2015) Cap-dependent, scanning-free translation initiation mechanisms. Biochim Biophys Acta 11:1313-1318

Han SC, Sun SQ, Li PH, Liu Q, Zhang ZH, Dong H, Sun MM, Wu WX, Wang XJ, Guo HC (2020) Ribosomal protein L13 promotes IRES-driven translation of FMDV in helicase DDX3-dependent manner. J Virol 94(2):e01679-e1719

Hertz MI, Landry DM, Willis AE, Luo G, Thompson SR (2013) Ribosomal protein S25 dependency reveals a common mechanism for diverse internal ribosome entry sites and ribosome shunting. Mol Cell Biol 33(5):1016-1026

Higgins R, Gendron JM, Rising L, Mak R, Webb K, Kaiser SE, Zuzow N, Riviere P, Yang B, Fenech E, Tang X, Lindsay SA, Christianson JC, Hampton RU, Wasserman SA, Bennett EJ (2015) 
The unfolded protein response triggers site-specific regulatory ubiquitylation of 40S ribosomal proteins. Mol Cell 59(1):35-49

Hilton A, Mizzen L, MacIntyre G, Cheley S, Anderson R (1986) Translational control in murine hepatitis virus infection. J Gen Virol 67(Pt 5):923-932

Hiscox JA, Wurm T, Wilson L, Britton P, Cavanagh D, Brooks G (2001) The coronavirus infectious bronchitis virus nucleoprotein localizes to the nucleolus. J Virol 75(1):506-512

Hong SW, Kim SM, Jin DH, Kim YS, Hur DY (2017) RPS27a enhances EBV-encoded LMP1-mediated proliferation and invasion by stabilizing of LMP1. Biochem Biophys Res Commun 491(2):303-309

Huang JY, Su WC, Jeng KS, Chang TH, Lai MM (2012) Attenuation of $40 \mathrm{~S}$ ribosomal subunit abundance differentially affects host and HCV translation and suppresses HCV replication. PLoS Pathog 8(6):e1002766

Irigoyen N, Firth AE, Jones JD, Chung BY, Siddell SG, Brierley I (2016) High-resolution analysis of coronavirus gene expression by RNA sequencing and ribosome profiling. PLOS Pathog 12(2): 1005473

Izumi RE, Valdez B, Banerjee R, Srivastava M, Dasgupta A (2001) Nucleolin stimulates viral internal ribosome entry site-mediated translation. Virus Res 76(1):17-29

Jack K, Bellodi C, Landry DM (2011) rRNA pseudouridylation defects affect ribosomal ligand binding and translational fidelity from yeast to human cells. Mol Cell 44(4):660-666

Jalal C, Uhlmann-Schiffler H, Stahl H (2007) Redundant role of DEAD box proteins p68 (Ddx5) and p72/p82 (Ddx17) in ribosome biogenesis and cell proliferation. Nucleic Acids Res 35(11):3590-3601

Jamieson KV, Wu J, Hubbard SR, Meruelo D (2008) Crystal structure of the human laminin receptor precursor. J Biol Chem 283(6):3002-3005

Jha S, Rollins MG, Fuchs G, Procter DJ, Hall EA, Cozzolino K, Sarnow P, Savas JN, Walsh D (2017) Trans-kingdom mimicry underlies ribosome customization by a poxvirus kinase. Nature 546(7660):651-655

Jiang N, Hu L, Liu C, Gao X, Zheng S (2015) 60S ribosomal protein L35 regulates beta-casein translational elongation and secretion in bovine mammary epithelial cells. Arch Biochem Biophys 583:130-139

Kaerlin M, Horak I (1978) Identification and characterization of ribosomal proteins phosphorylated in vaccinia-virus-infected HeLa cells. Eur J Btochem 90(3):463-469

Kapp LD, Lorsch JR (2004) The molecular mechanics of eukaryotic translation. Annu Rev Biochem 73:657-704

Karlas A, Machuy N, Shin Y, Pleissner KP, Artarini A, Heuer D, Becker D, Khalil H, Ogilvie LA, Hess S, Maurer AP, Muller E, Wolff T, Rudel T, Meyer TF (2010) Genome-wide RNAi screen identifies human host factors crucial for influenza virus replication. Nature 463(7282):818-822

Karniely S, Weekes MP, Antrobus R, Rorbach J, van Haute L, Umrania Y, Smith DL, Stanton RJ, Minczuk M, Lehner PJ, Sinclair JH (2016) Human cytomegalovirus infection upregulates the mitochondrial transcription and translation machineries. mBio 7(2): $\mathrm{e} 00029$

Kennedy IM, Leader DP (1981) Increased phosphorylation of ribosomal protein S6 in hamster fibroblasts transformed by polyoma virus and simian virus 40. Biochem J 198(1):235-237

Kennedy IM, Stevely WS, Leader DP (1981) Phosphorylation of ribosomal proteins in hamster fibroblasts infected with pseudorabies virus or herpes simplex virus. J Virol 39(2):359-366

Kerr CH, Ma ZW, Jang CJ, Thompson SR, Jan E (2016) Molecular analysis of the factorless internal ribosome entry site in Cricket Paralysis virus infection. Sci Rep 6:37319
Khatter H, Myasnikov AG, Natchiar SK, Klaholz BP (2015) Structure of the human 80S ribosome. Nature 520(7549):640-645

Kiburu IN, LaRonde-LeBlanc N (2012) Interaction of Rio1 kinase with toyocamycin reveals a conformational switch that controls oligomeric state and catalytic activity. PLoS ONE 7(5):e37371

Kim J, Kim YS (2018) Effect of HIV-1 Tat on the formation of the mitotic spindle by interaction with ribosomal protein S3. Sci Rep 8(1):8680

Kondrashov N, Pusic A, Stumpf CR, Shimizu K, Hsieh AC, Ishijima J, Shiroishi T, Barna M (2011) Ribosome-mediated specificity in Hox mRNA translation and vertebrate tissue patterning. Cell 145(3):383-397

Kressler D, Hurt E, Bassler J (2010) Driving ribosome assembly. Biochim Biophys Acta 1803(6):673-683

Lafontaine DL, Tollervey D (2001) The function and synthesis of ribosomes. Nat Rev Mol Cell Biol 2(7):514-520

Lam YW, Lamond AI, Mann M, Andersen JS (2007) Analysis of nucleolar protein dynamics reveals the nuclear degradation of ribosomal proteins. Curr Biol 17(9):749-760

Landry DM, Hertz MI, Thompson SR (2009) RPS25 is essential for translation initiation by the Dicistroviridae and hepatitis $\mathrm{C}$ viral IRESs. Genes Dev 23(23):2753-2764

Lawrence FJ, McStay B, Matthews DA (2006) Nucleolar protein upstream binding factor is sequestered into adenovirus DNA replication centres during infection without affecting RNA polymerase I location or ablating rRNA synthesis. J Cell Sci 119(Pt 12):2621-2631

Lee KM, Yu CW, Chan DS, Chiu TY, Zhu G, Sze KH, Shaw PC, Wong KB (2010) Solution structure of the dimerization domain of ribosomal protein $\mathrm{P} 2$ provides insights for the structural organization of eukaryotic stalk. Nucleic Acids Res 38(15):5206-5216

Lee AS, Burdeinick-Kerr R, Whelan SP (2013) A ribosome-specialized translation initiation pathway is required for cap-dependent translation of vesicular stomatitis virus mRNAs. Proc Natl Acad Sci U S A 110(1):324-329

Leopardi R, Roizman B (1996) Functional interaction and colocalization of the herpes simplex virus 1 major regulatory protein ICP4 with EAP, a nucleolar-ribosomal protein. Proc Natl Acad Sci U S A 93(10):4572-4576

Li S (2019) Regulation of ribosomal proteins on viral infection. Cells 8(5):508

Li Z, Hann SR (2013) Nucleophosmin is essential for c-Myc nucleolar localization and c-Myc-mediated rDNA transcription. Oncogene 32(15):1988-1994

Li S, Li X, Zhou Y (2018) Ribosomal protein L18 is an essential factor that promote rice stripe virus accumulation in small brown planthopper. Virus Res 247:15-20

Li Y, Fang L, Zhou Y, Tao R, Wang D, Xiao S (2018) Porcine reproductive and respiratory syndrome virus infection induces both eIF2 $\alpha$ phosphorylation-dependent and -independent host translation shutoff. J Virol 92(16):e00600-e618

Liu QH, Ma FF, Guan GK, Wang XF, Li C, Huang J (2015) White spot syndrome virus VP51 interact with ribosomal protein L7 of Litopenaeus vannamei. Fish Shellfish Immunol 44(1):382-388

Love RA, Parge HE, Wickersham JA, Hostomsky Z, Habuka N, Moomaw EW, Adachi T, Hostomska Z (1996) The crystal structure of hepatitis $\mathrm{C}$ virus NS3 proteinase reveals a trypsin-like fold and a structural zinc binding site. Cell 87(2):331-342

Majzoub K, Hafirassou ML, Meignin C, Goto A, Marzi S, Fedorova A, Verdier Y, Vinh J, Hoffmann JA, Martin F, Baumert TF, Schuster C, Imler JL (2014) RACK1 controls IRES-mediated translation of viruses. Cell 159(5):1086-1095

Malygin AA, Bondarenko EI, Ivanisenko VA, Protopopova EV, Karpova GG, Loktev VB (2009) C-terminal fragment of human laminin-binding protein contains a receptor domain 
for venezuelan equine encephalitis and tick-borne encephalitis viruses. Biochemistry (Mosc) 74(12):1328-1336

Martinez-Salas E, Francisco-Velilla R, Fernandez-Chamorro J, Lozano G, DiazToledano R (2015) Picornavirus IRES elements: RNA structure and host protein interactions. Virus Res 206:62-73

May KL, Li XP, Martinez-Azorin F, Ballesta JP, Grela P, Tchórzewski M, Tumer NE (2012) The P1/P2 proteins of the human ribosomal stalk are required for ribosome binding and depurination by ricin in human cells. FEBS J 279(20):3925-3936

Mekdad HE, Boutant E, Karnib H, Biedma ME, Sharma KK, Malytska I, Laumond G, Roy M, Réal E, Paillart JC, Moog C, Darlix JL, Mély Y, de Rocquigny H (2016) Characterization of the interaction between the HIV-1 Gag structural polyprotein and the cellular ribosomal protein $\mathrm{L} 7$ and its implication in viral nucleic acid remodeling. Retrovirology 13(1):54

Melén K, Tynell J, Fagerlund R, Roussel P, Hernandez-Verdun D, Julkunen I (2012) Influenza A H3N2 subtype virus NS1 protein targets into the nucleus and binds primarily via its $\mathrm{C}$-terminal NLS2/NoLS to nucleolin and fibrillarin. Virol J 9:167

Meng W, Han SC, Li CC, Dong HJ, Wang XJ (2018) Multifunctional viral protein 345 manipulates nucleolar protein NOP53 for optimal viral replication of HSV-1. Cell Death Dis 9(2):103

Meng W, Wang XJ, Wang HCR (2019) Targeting nuclear proteins for control of viral replication. Crit Rev MicrobioI 45(5-6):495-513

Moore PB (2012) How should we think about the ribosome? Annu Rev Biophys 41:1-19

Naganuma T, Shiogama K, Uchiumi T (2007) The N-terminal regions of eukaryotic acidic phosphoproteins $\mathrm{P} 1$ and $\mathrm{P} 2$ are crucial for heterodimerization and assembly into the ribosomal GTPaseassociated center. Genes Cells 12(4):501-510

Narayanan K, Huang C, Lokugamage KG, Kamitani W, Ikegami T, Tseng CT, Makino S (2008) Severe acute respiratory syndrome coronavirus nsp1 suppresses host gene expression, including that of type I interferon, in infected cells. J Virol 82(9):4471-4479

Ohn T, Kedersha N, Hickman T, Tisdale S, Anderson P (2008) A functional RNAi screen links O-GlcNAc modification of ribosomal proteins to stress granule and processing body assembly. Nat Cell Biol 10(10):1224-1231

Olivares E, Landry DM, Cáceres CJ, Pino K, Rossi F, Navarrete C, Huidobro-Toro JP, Thompson SR, López-Lastra M (2014) The 5 untranslated region of the human T-cell lymphotropic virus type 1 mRNA enables cap-independent translation initiation. J Virol 88(11):5936-5955

Peeples ME, Wang C, Gupta KC, Coleman N (1992) Nuclear entry and nucleolar localization of the Newcastle disease virus (NDV) matrix protein occur early in infection and do not require other NDV proteins. J Virol 66(5):3263-3269

Ríman J, Sverak L, Langlois AJ, Bonar RA, Beard JW (1969) Influence of toyocamycin on RNA synthesis in chick embryo cells noninfected and infected with strain MC29 avian leukosis virus. Cancer Res 29(9):1707-1716

Rocak S, Linder P (2004) DEAD-box proteins: the driving forces behind RNA metabolism. Nat Rev Mol Cell Biol 5(3):232-241

Sabila M, Kundu N, Smalls D, Ullah H (2016) Tyrosine phosphorylation based homo-dimerization of arabidopsis RACK1A proteins regulates oxidative stress signaling pathways in yeast. Front Plant Sci 7:176

Shen CL, Liu CD, You RI, Ching YH, Liang J, Ke L, Chen YL, Chen HC, Hsu HJ, Liou JW, Kieff E, Peng CW (2016) Ribosome protein L4 is essential for Epstein-Barr Virus nuclear antigen 1 function. Proc Natl Acad Sci U S A 113(8):2229-2234

Shi Z, Barna M (2015) Translating the genome in time and space: specialized ribosomes, RNA regulons, and RNA-binding proteins. Annu Rev Cell Dev Biol 31:31-54
Shi Z, Fujii K, Kovary KM, Genuth NR, Röst HL, Teruel MN, Barna M (2017) Heterogeneous ribosomes preferentially translate distinct subpools of mRNAs genome-wide. Mol Cell 67(1):71-83

Simonin D, Diaz JJ, Kindbeiter K, Denoroy L, Madjar JJ (1995) Phosphorylation of ribosomal protein L30 after herpes simplex virus type 1 infection. Electrophoresis 16(5):854-859

Simsek D, Tiu GC, Flynn RA, Byeon GW, Leppek K, Xu AF, Chang HY, Barna M (2017) The mammalian ribo-interactome reveals ribosome functional diversity and heterogeneity. Cell 169(6):1051-1065

Slavov N, Semrau S, Airoldi E, Budnik B, van Oudenaarden A (2015) Differential stoichiometry among core ribosomal proteins. Cell Rep 13(5):865-873

Slawson C, Housley MP, Hart GW (2006) O-GlcNAc cycling: how a single sugar post-translational modification is changing the way we think about signaling networks. J Cell Biochem 97(1):71-83

Su WC, Hsu SF, Lee YY, Jeng KS, Lai MM (2015) A nucleolar protein, ribosomal RNA processing 1 homolog B (RRP1B), enhances the recruitment of cellular mRNA in influenza virus transcription. $\mathrm{J}$ Virol 89(22):11245-11255

Svetlov MS, Vázquez-Laslop N, Mankin AS (2017) Kinetics of drugribosome interactions defines the cidality of macrolide antibiotics. Proc Natl Acad Sci U S A 114(52):13673-13678

Sydorskyy Y, Dilworth DJ, Halloran B, Yi EC, Makhnevych T, Wozniak RW, Aitchison JD (2005) Nop53p is a novel nucleolar 60S ribosomal subunit biogenesis protein. Biochem J 388(Pt 3):819-826

Tafforeau L, Zorbas C, Langhendries JL, Mullineux ST, Stamatopoulou V, Mullier R, Wacheul L, Lafontaine DL (2013) The complexity of human ribosome biogenesis revealed by systematic nucleolar screening of Pre-rRNA processing factors. Mol Cell 51(4):539-551

Tereshchenkov AG, Dobosz-Bartoszek M, Osterman IA, Marks J, Sergeeva VA, Kasatsky P, Komarova ES, Stavrianidi AN, Rodin IA, Konevega AL, Sergiev PV, Sumbatyan NV, Mankin AS, Bogdanov AA, Polikanov YS (2018) Binding and action of amino acid analogs of chloramphenicol upon the bacterial ribosome. J Mol Biol 430(6):842-852

Thomson E, Tollervey D (2005) Nop53p is required for late 60S ribosome subunit maturation and nuclear export in yeast. RNA 11(8):1215-1224

Thrower JS, Hoffman L, Rechsteiner M, Pickart CM (2000) Recognition of the polyubiquitin proteolytic signal. EMBO J 19(1):94-102

Torrecilla J, Del Pozo-Rodríguez A, Solinís MÁ, Apaolaza PS, Berzal-Herranz B, Romero-López C, Berzal-Herranz A, RodríguezGascón A (2016) Silencing of hepatitis C virus replication by a non-viral vector based on solid lipid nanoparticles containing a shRNA targeted to the internal ribosome entry site (IRES). Colloids Surf B Biointerfaces 146:808-817

Ullah H, Hou W, Dakshanamurthy S, Tang Q (2019) Host targeted antiviral (HTA): functional inhibitor compounds of scaffold protein RACK1 inhibit herpes simplex virus proliferation. Oncotarget 10(35):3209-3226

Urano D, Czarnecki O, Wang X, Jones AM, Chen JG (2015) Arabidopsis receptor of activated $\mathrm{C}$ kinase1 phosphorylation by WITH NO LYSINE8 KINASE. Plant Physiol 167(2):507-516

Waggoner S, Sarnow P (1998) Viral ribonucleoprotein complex formation and nucleolar-cytoplasmic relocalization of nucleolin in poliovirus-infected cells. J Virol 72(8):6699-6709

Wakefield L, Brownlee GG (1989) RNA-binding properties of influenza A virus matrix protein M1. Nucleic Acids Res 17(21):8569-8580

Walczak CP, Leto DE, Zhang L, Riepe C, Muller RY, DaRosa PA, Ingolia NT, Elias JE, Kopito RR (2019) Ribosomal protein RPL26 is the principal target of UFMylation. Proc Natl Acad Sci U S A 116(4):1299-1308 
Wang J, Yang X, Zhou P, Han H (2002) Cloning of mouse genomic ribosomal protein $\mathrm{L} 6$ gene and analysis of its promoter. Biochim Biophys Acta 1576(1-2):219-224

Wang B, Duan X, Fu M, Liu Y, Wang Y, Li X, Cao H, Zheng SJ (2018) The association of ribosomal protein L18 (RPL18) with infectious bursal disease virus viral protein VP3 enhances viral replication. Virus Res 245:69-79

Wang L, Xu Y, Rogers H, Saidi L, Noguchi CT, Li H, Yewdell JW, Guydosh NR, Ye Y (2019) UFMylation of RPL26 links translocation-associated quality control to endoplasmic reticulum protein homeostasis. Cell Res 30(1):5-20

Wertz GW, Youngner JS (1970) Interferon production and inhibition of host synthesis in cells infected with vesicular stomatitis virus. J Virol 6(4):476-484

Westdorp KN, Terhune SS (2018) Impact of RNA polymerase I inhibitor CX-5461 on viral kinase-dependent and -independent cytomegalovirus replication. Antiviral Res 153:33-38

Whitlow ZW, Connor JH, Lyles DS (2008) New mRNAs are preferentially translated during vesicular stomatitis virus infection. $\mathrm{J}$ Virol 82(5):2286-2294

Wilson DN, Doudna Cate JH (2012) The structure and function of the eukaryotic ribosome. Cold Spring Harb Perspect Biol 4(5):a011536

Wood J, Frederickson RM, Fields S, Patel AH (2001) Hepatitis C virus 3 'X region interacts with human ribosomal proteins. J Virol 75(3):1348-1358

Xue S, Barna M (2012) Specialized ribosomes: a new frontier in gene regulation and organismal biology. Nat Rev Mol Cell Biol 13(6):355-369

Xue S, Tian S, Fujii K, Kladwang W, Das R, Barna M (2015) RNA regulons in Hox 5' UTRs confer ribosome specificity to gene regulation. Nature 517(7532):33-38

Yang Z, Cao S, Martens CA, Porcella SF, Xie Z, Ma M, Ben S, Moss B (2015) Deciphering poxvirus gene expression by RNA sequencing and ribosome profiling. J Virol 89(13):6874-6886

You J, Dove BK, Enjuanes L, DeDiego ML, Alvarez E, Howell G, Heinen P, Zambon M, Hiscox JA (2005) Subcellular localization of the severe acute respiratory syndrome coronavirus nucleocapsid protein. J Gen Virol 86(Pt 12):3303-3310
Yu X, Hathout Y, Fenselau C, Sowder RC, Henderson LE, Rice WG, Mendeleyev J, Kun E (1995) Specific disulfide formation in the oxidation of HIV-1 zinc finger protein nucleocapsid p7. Chem Res Toxicol 8(4):586-590

Yu Y, Maggi LB Jr, Brady SN, Apicelli AJ, Dai MS, Lu H, Weber JD (2006) Nucleophosmin is essential for ribosomal protein L5 nuclear export. Mol Cell Biol 26(10):3798-3809

Zachara NE, Hart GW (2004) O-GlcNAc a sensor of cellular state: the role of nucleocytoplasmic glycosylation in modulating cellular function in response to nutrition and stress. Biochim Biophys Acta 1673(1-2):13-28

Zachara NE, Hart GW (2006) Cell signaling, the essential role of O-GlcNAc. Biochim Biophys Acta 1761(5-6):599-617

Zhang X, Gao X, Coots RA, Conn CS, Liu B, Qian SB (2015) Translational control of the cytosolic stress response by mitochondrial ribosomal protein L18. Nat Struct Mol Biol 22(5):404-410

Zhou X, Luo J, Mills L, Wu S, Pan T, Geng G, Zhang J, Luo H, Liu C, Zhang H (2013) DDX5 facilitates HIV-1 replication as a cellular co-factor of Rev. PLoS ONE 8(5):e65040

Zhou X, Liao WJ, Liao JM, Liao P, Lu H (2015) Ribosomal proteins: functions beyond the ribosome. J Mol Cell Biol 7(2):92-104

Zhu Z, Li W, Zhang X, Wang C, Gao L, Yang F, Cao W, Li K, Tian H, Liu X, Zhang K, Zheng H (2019) Foot-and-mouth disease virus capsid protein VP1 interacts with host ribosomal protein SA to maintain the activation of MAPKs signal pathway and promote virus replication. J Virol 94:e01350-e1419

Zidane N, Ould-Abeih MB, Petit-Topin I, Bedouelle H (2012) The folded and disordered domains of human ribosomal protein SA have both idiosyncratic and shared functions as membrane receptors. Biosci Rep 33(1):113-124

Publisher's Note Springer Nature remains neutral with regard to jurisdictional claims in published maps and institutional affiliations. 